\title{
Letter to the Editors
}

\section{Choice of first antihypertensive - are existing guidelines ignored? Response to Vegter \& de Jong-van den Berg.}

\section{Ifeanyi Okechukwu, Azra Mahmud, Kathleen Bennett \& John Feely}

Department of Pharmacology and Therapeutics, Trinity Centre for Health Sciences, St James's Hospital, Dublin, Ireland

We agree with the overall conclusions of Vegter et al. [1], whose data show a similar choice of first antihypertensives to that reported in Ireland.

We now represent our data as requested, using likelihood to receive recommended therapy for 'young males vs. old males', which shows an odds ratio $(\mathrm{OR})=1.75[95 \%$ confidence interval $(\mathrm{Cl}) 1.63,1.88$ ] and for 'young females vs. older females', OR $=1.11$ ( $95 \% \mathrm{Cl} 1.06,1.17)$.

We suggest that the reasons for similar findings in a number of different countries are not necessarily the same. For example, as distinct from the Netherlands, in Ireland we do not have pharmacotherapy audit meetings or strong national guidelines. However, we do agree that other factors may influence the choice of antihypertensive therapy. It is interesting to observe that, despite adverse publicity concerning $\beta$-blockers as first-line antihypertensive agents, in both countries, as seen in these studies, they have remained among the most popular antihypertensive groups [1,2].

\section{REFERENCES}

1 Vetger S, de Jong-van den Berg LTW. Choice of first antihypertensive - comparison between Irish and Dutch setting. Br J Clin Pharmacol 2008; 66:313-5.

2 Okechukwu I, Mahmud A, Bennett K, Feely J. Choice of first antihypertensive - are existing guidelines ignored? $\mathrm{Br} \mathrm{J}$ Clin Pharmacol 2007; 64: 722-5.

\section{RECEIVED}

14 March 2008

\section{ACCEPTED}

17 March 2008

\section{CORRESPONDENCE}

Ifeanyi Okechukwu, Department of Pharmacology and Therapeutics, Trinity Centre for Health Sciences, St James's Hospital, Dublin 8, Ireland.

E-mail: okechuki@tcd.ie 